\title{
Effect of Time Pressure at Tactical Level Managing Disaster
}

\section{Agoston Restas}

Institute of Disaster Management, National University of Public Service, Budapest, Hungary

Email: Restas.Agoston@uni-nke.hu

How to cite this paper: Restas, A. (2016) Effect of Time Pressure at Tactical Level Managing Disaster. World Journal of Engineering and Technology, 4, 93-100. http://dx.doi.org/10.4236/wjet.2016.43C012

Received: July 19, 2016

Accepted: September 25, 2016

Published: September 28, 2016

\begin{abstract}
Introduction: Disaster management can face to emergency situation without any pre-sign and even if it has forecast they can meet the requirements of improvisation making their decision. Improvisation can be taken at any level of the management (strategic, operational and tactical) but at tactical level the time press is certainly the biggest problem. This article focuses on tactical level and shows some method to compensate time press. Method: Author studied relevant literatures and used own experience as a firefighting manager. Other studies made by the author previously were also used. Results: Without time press disaster managers can use analytical thinking but in case of time press they must prefer critical thinking, satisfactory procedures or management by exceptions but creativity and heuristics are also used in their decision. Author created a complex model of decision making in emergency: building on practical experience the above mechanisms together with the internal triggers hold as pillars the recognition-primed decisions on which locate the principals of disaster management.
\end{abstract}

\section{Keywords}

Model of Decision Making in Emergency, Critical Thinking, Satisfactory Procedures, Management by Exceptions, Creativity, Heuristics

\section{Introduction}

An important element of the activities of emergency responders is that they cannot or only to a very limited extent can modify the terms of the task, improve them as desired. Despite the differences of environment, indications of the complexity of the situation, the possibility of the radical change in the given situation, uncertainty and ambiguity of the information available can be recognized and well identified. Most of these factors are present; occasionally all of them may be present at a certain level of emergency de- 
cisions: including the strategic, operational and tactical levels, but certainly with a different focus or at different times. On strategic and operational level, in general, not only more time is available, but also human and technical resources are at hand more broadly, and decision support instruments as well to reduce uncertainties occurring. All of them stand implicit at the background of the intervention's safety, which is priority during the intervention and also very important and complex question at tactical level [1] [2].

The different scopes of tasks exist in different environments and structures, so the solution of similar basic problem also exists in other dimensions. Based on author's own experience, the more extensive case we are dealing with in time, the more the above factors cumulatively prevail, but because of the protracted implementation, it is, however, easier to solve them. The most limiting factor from the above is time, proven by essays and presentations firefighters made and author investigated. This provides a framework impossible to burst and a forced drift, a pressurized channel for the decision-maker, entangled in which one can no longer break free. The functional background of decisions made in a short time, their mechanism different from the conventional was studied in latest time, and gave the name recognition-primed decision to this special decision procedure.

\section{Mechanisms Complementing a Recognition-Primed Decision}

Different triggers, internal resources ensure the operation of recognition-primed decisions. Klein, in his work, assumes 5 markedly distinct abilities, these are intuition, imagination, perception of the invisible, the ability to formulate, metaphors and analogies [3]. In the joint work of Cohen, Freeman and Thomson [4], draws the attention to the importance and benefits of critical thinking as criticism of actions planned by ourselves.

Despite the fact that one could assume, that recognition-primed decision-making enjoys exclusivity on a tactical level, it is absolutely not true. We can compare it with several disasters or incidents, still, one of the essential features is that it protracts in time. It allows the decision-maker to think over the situation, collect information, develop action versions and consider. Floods or forest fires develop for several days or hours and covering a large area. During protracted decision-making, the recognitionprimed processes, based on author's experience, proved to be irreplaceable assistance rather in solving partial tasks.

\subsection{Analytical Thinking}

Killion sees the combination of recognition-primed decision-making with the analyzing and evaluating procedure in two ways [5]. In both cases, the conditions are that adequate time should be available for analyzing the options. In the first case, prior to recognition-primed decisions, focusing on the given circumstances, we set up options and analyze them. In the second case, a more detailed analysis of the action version of our recognition-primed decision may take place. In the latter case, the spectrum of the task is obviously significantly narrower than in the first case. The two mechanisms, de- 
pending on the situation, can be harmonized or one of them may become predominant.

The observation of the elemental parts of multi-aspect decision-making shows that decision-makers divide complex problems to smaller and smaller partial problems until they become such a basic level problem that a decision-maker is able to solve even with little effort [6]. This latter process can also be a recognition-primed decision-making, but logically we can find Duggan's view [7], according to which successful decisionmakers not perceive a problem until they can solve it.

\subsection{Critical Thinking on a Tactical Level}

Cohen, Freeman and Wolf studied the possible decision support role of critical thinking on a tactical decision-making level [4]. In their work, active naval officers and case reports were studied based on which they state that experienced emergency decision-makers, in new situations, using their previous experience, make decisions with help of recognition-primed mechanisms. Cohen's model explains in detail the critical analytical strategies that contribute to the operation of recognition-primed thinking. Systematic situation models often based on informal narratives as schemes organize our information in cause and effect relationship in individual cases and underpin the development of recognition-primed thinking.

One of the most important elements of Cohen's model is the quick test. A quick test is a higher-level control mechanism for critical analysis and its accuracy. Its recognition strategies are formed, similarly to other decision-making processes, by the success or failure experience of past events. The complex recognition mechanism comes to the fore when the demand on time and resources for critical analysis is overweighed. It is possible in three well-definable cases [4]. A quick test considers the conditions in the light of the above factors, and if appropriate, prevents recognition-primed decision, and focuses on critical thinking. When circumstances are not adequate, a quick test will allow for an instant reply.

\subsection{Satisfactory Procedure Mechanism}

We have seen previously that an emergency manager's time to make a decision is limited. Since this time limit precludes the possibility to carry out the necessary analyses of the classic model, objectively the choice of an optimum option is not achievable for a decision-maker. In response to the difficulties of the collection of information and the reduction of the costs in relation, a decision-maker does not strive for optimum results, but, depending on the circumstances, settles for satisfactory solutions.

The above process, different from analytical thinking, is enforced by several factors. Some of these factors are the impossibility of obtaining all information necessary to select the best solution, or the shortage of time; the latter induces a compulsion of decision-making. The limited nature of the processing information available is also of significant influence. Filtering the information, and by this the selection of response to the tasks is necessary because the capacity of our short-term memory is quite limited. According to Miller's studies, it allows the parallel processing of only $7 \pm 2$ bits of infor- 
mation at one time [8]. If emergency manager made all the basic decisions, his decision-making capacity would be immediately exhausted at a complex task.

Despite the small capacity, thanks to recognition-primed mechanisms, correct decision is made in most cases. An emergency manager, using his experience, in situations not requiring decisions different from the previous solutions, implement automatic measures, protocol procedures, thus continuously maintains his decision-making capacity. In this case, using his own experience, an emergency manager is not interested in the series of best elementary decisions used to eliminate the problem, but only in satisfying the conditions of professional work through the decisions made as a whole.

\subsection{Decisions by Exceptions}

The aim of the application of the method is that the leadership responsibilities of managers should be drastically reducible; its essence is that we should only intervene into processes having permanent characteristics in majority, if they cross the pre-specified lower and upper limits. The method, management by sensitive exception, so derived from the dynamics of the processes, the necessary interventions are now possible even before crossing the borders [9]. The method of management by exceptions, based on author's experience, is the greatest help for a firefighting manager to continuously maintain his decision capacity. It can appear in different ways, like protocol procedures, individual way of speaking, silence approval, peripheral vision, and informationprocessing in zones.

The experience and competence of the persons performing a given activity allows every firefighter to make his basic decisions in his own field of work. This shows the arrangement in zones of information processing (Figure 1). Of course, not every incident or moment requires response. This zone does not require action that is practically ignored by a firefighter, because it is a natural consequence of extinguishing. A significant part of problems outside the zone, as a result of a firefighter's decision in that location,

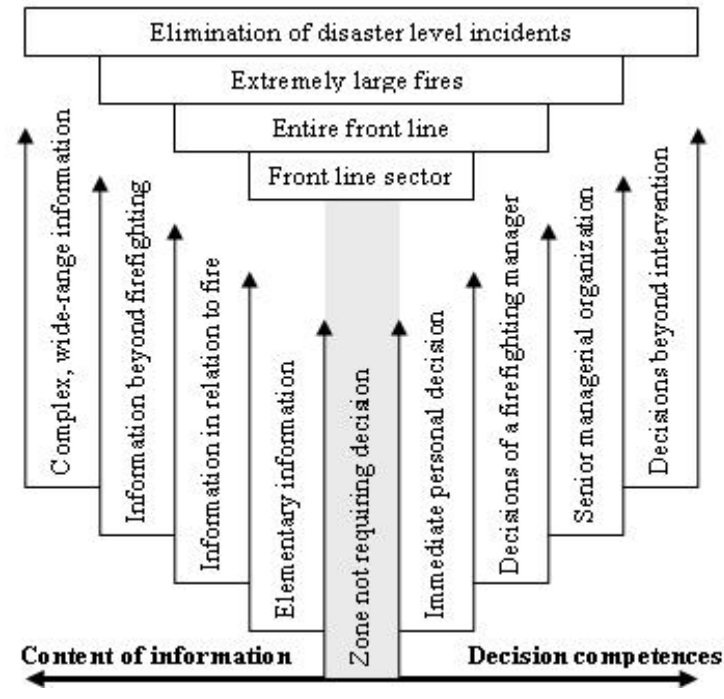

Figure 1. Decisions based on exceptions in firefighting view. Source: Author. 
is solved by intervention (firefighting), this information now reaches the firefighting manager, but he usually does not require a decision yet. A firefighting manager manages the problems outside this zone that exceed the decision-making competence of subordinate firefighters. This originates in the fact that, on the one hand, based on the information from reconnaissance and radio traffic, he can create a comprehensive and dynamic picture of the entire process, the evolvement of fire or the efficiency of extinguishing, on the other hand, legislation entitles firefighting managers to take actions.

\subsection{Creativity}

Creativity has many definitions. Munteanu, in one of his works, presents 35, which approach creativity, in different ways, however, there is no single definition generally accepted or used, either [10]. Analyses researching creativity show that there are three general directions of study [11]. The first concerns the nature of creative thinking, the second one the development of creativity and the third one the characterizing properties of creative people. Amongst the properties, there is practically none, which would not be advantageous for efficient work in a special environment describing the working conditions of managing disasters. Based on the above the creative capabilities of an emergency manager can be explicitly beneficial for facilitating the technically correct decisions relating to managing emergency situations.

Creativity can significantly increase professional efficiency of decisions made by emergency managers in unexpected situations. This can be seen when first aid medical service, special rescue teams or firefighters are able to turn local conditions, in a moment, into exploitable advantages. However, author found that a significant part of properties characterizing innovativeness do not prefer everyday work, free of interventions, in structured organizations, in respect of firefighting managers. This is confirmed by research findings as well, according to which it is explicitly problematic to follow strict rules for people producing creative results (The Reader's Digest Association Ltd., 1992).

\subsection{Heuristics}

Heuristics means that certain distortions are not incidental and unarranged errors, but the results of simplifying mechanisms, with which decision-makers make the complicated tasks manageable for themselves, which cut the Gordian knot [12]. Based on researches related to the names Tversky and Kahneman, we distinguish 5 basic groups of heuristics [13]. These are representativeness, availability, fixing (imprint) and adjustment heuristics, retrospective distortion, as well as overconfidence and calibration. Studying the activities of firefighting managers, there are many examples of practical heuristics.

Overconfidence, based on author's judgement, is one of the greatest risk factors of the efficiency of decisions of an emergency manager. They, quite often, stops searching for the information necessary earlier than sufficient, based on his experience, he trusts his own judgement, many times, assuming unnecessary risks. The extent of rational risk 
assumed during interventions should be always chosen proportionately to the given task.

Researches show that overconfidence means that the division between actual and putative knowledge is around 50\% [14]. We are best able to judge the certainty of our decisions around $80 \%$ of knowledge, over this value, we underestimate our abilities. The above have shown that our actual knowledge does not grow parallel with certainty; the increase of our knowledge does not automatically mean the growth of self-assurance [12]. During intervention the characteristic of the given environment exactly expresses that the actual knowledge of a decision-maker can only be partial, he can only be sure temporarily of the reliability of his knowledge. Aggregating the above, we can see that the risk of overconfidence continuously prevails in the decisions of an emergency manager.

\section{Summarizing and Modelling of Decision-Making in Emergency}

If not enough time is available for analyzing and evaluating decision-making, recognition-primed procedures receive a greater role. Critical thinking uses recognition procedures, during which the decision-making process can be accelerated or analyzed with the help of a quick test and depending on the time available. The quick test, considering the circumstances, hinders recognition-primed decision and prefers critical thinking. However, when the circumstances are inappropriate for critical analyzing thinking, the quick test allows immediate reply.

Despite the limited decision capacity, thanks to recognition-primed mechanisms, in most of the occasions, correct decisions are made by emergency managers. Time limit precludes the possibility for the manager to carry out analyses necessary for the classic model; therefore, the selection of the optimal possibility is objectively not attainable by the decision-maker. The decision-maker is not striving to achieve ideal results, as a response to the difficulties of collecting information and reducing costs in relation, but depending on the circumstances, he is satisfied with its satisfactory solution.

By reducing the time available for decision-making and for maintaining decisionmaking capacity, an emergency manager applies the management (decision-making) method based on exceptions in numerous situations. Its essence is that several moments of interventions proceed protocol-like, thus, they need not be controlled all the time; on the other hand, not all the phases of the processes require direct management decision.

During the study of creativity, author has concluded that there is no feature characteristic of the working circumstances of emergency managers that would not be advantageous to perform efficient work in a special environment. Therefore, it is sure that the creative capabilities of emergency managers can be explicitly advantageous to facilitate the professionally correct decisions on interventions even if a significant part of the characteristics of innovativeness does not favor the performance of an everyday work free of interventions.

Heuristics are not random-like errors or specific distortions facilitating our everyday 


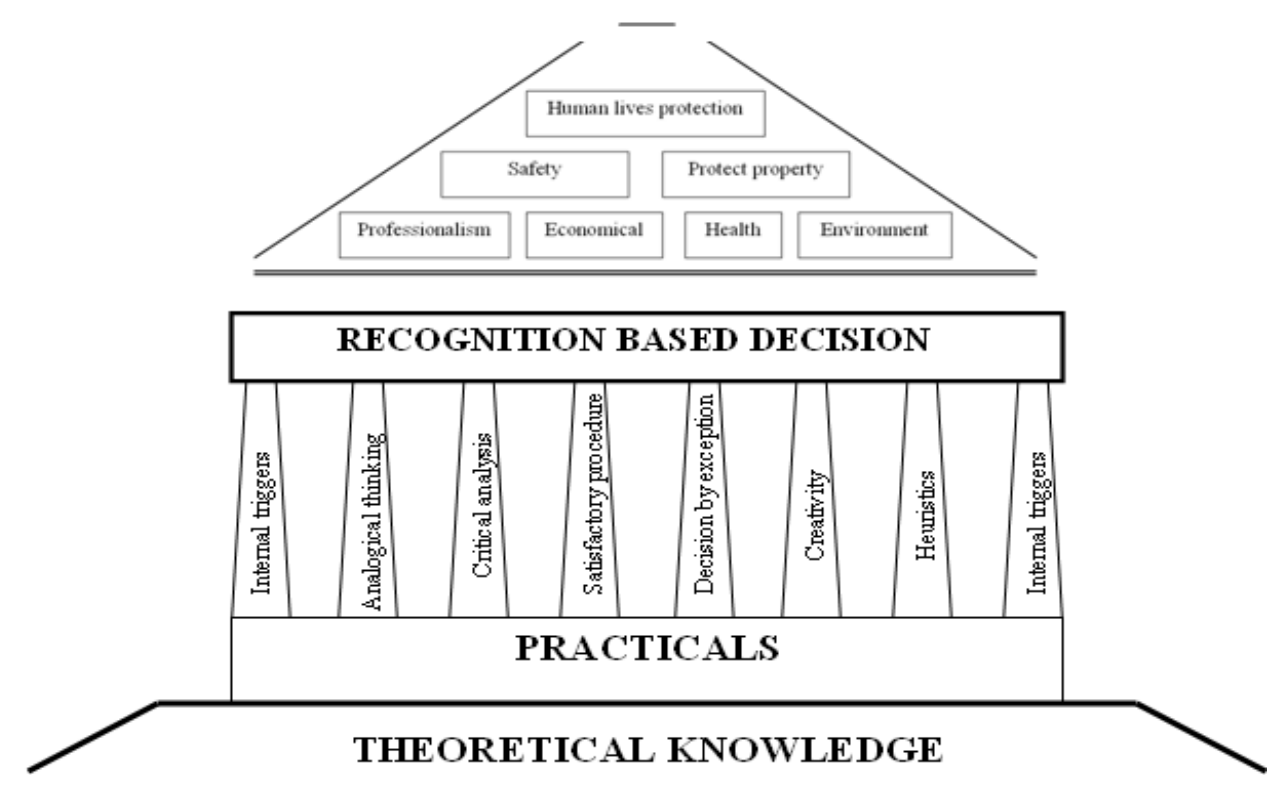

Figure 2. Complex model of decision-making of disaster managers. Source: Author.

activities. These are the results of simplifying mechanisms, through which decisionmakers can make difficult tasks manageable for themselves. Besides the benefits of heuristics, the greatest challenge for an emergency manager can mean the inherent erroneous distortions, which surely often help, but their uncritical acceptance, in certain cases, can end up in fatal dangers. The declared objective and sense of the decisions of emergency managers is the efficient implementation of interventions. It is symbolized by the principles of emergency management with structured division, on the top of which we clearly find the saving of human lives.

Emergency managers certainly have less time to make their decisions compared to the time interval of classic decisions, so, their decision mechanism is strongly based on recognition procedures due to the peculiar environment, and the limited process possibility of simultaneous pieces of information. The competence of emergency managers is based on the unity of theoretical knowledge and practical experience. Building on practical experience, the different mechanisms like analogical thinking, critical analysis, satisfactory procedure, decisions based on exceptions, creativity and heuristics, together with the internal triggers, hold as pillars and make recognition-primed decision procedure of emergency managers operational. Author illustrates the above as a complex system of emergency decision-making of disaster managers in Figure 2.

\section{Fund}

Above research was supported by the project titled: "Public Service Development Establishing Good Governance, PADOP-2.1.2-CCHOP-15-2016-00001" at the National University of Public Service, Budapest, Hungary.

\section{References}

[1] Pántya, P. (2011) Hatékonyság és biztonság növelése az osztó vonala mögött (Effectiveness 
of the Firefighting Intervention behind the Frontline). Védelem, 1-8.

[2] Kolonics, G. and Kóródi, Gy. (2003) The Examination of the Role of Natural Substances in the Protection Against UV Radiation. Hadmérnök, VIII, 339-344.

[3] Klein, G.A. (1999) Sources of Power: How People Make Decisions. MIT Press, Cambridge, MA.

[4] Cohen, S.M., Freeman, J.T. and Thompson, B.B. (1996) Integrated Critical Thinking Training and Decision Support for Tactical Anti-Air Warfare; Report, Cognitive Technologies, Inc., Naval Air Warfare Center Training System Division, Contract No. N61339-96R-0046.

[5] Killion, T.H. (2000) Decision Making and the Levels of War; Military Review, United States Army Combined Arms Center, Fort Leavenworth, Kansas, US.

[6] Simon, H.A. (1960) The New Science of Management Decisions. Harper \& Brother, New York. http://dx.doi.org/10.1037/13978-000

[7] Duggan (2002) Napoleon's Glance: The Secret of Strategy. Nation/Avalon, New York, 17.

[8] Miller, G.A. (1956) The Magic Number 7 Plus or Minus 2; Some Limits on our Capacity for Processing Information. Psychology Review, 63. http://dx.doi.org/10.1037/h0043158

[9] Hoványi, G. (2002) A menedzsment új horizontjai (New Horizon of the Management); Közgazdasági Szemle, XLIX, 251-264.

[10] Munteanu, A. (1994) Incursiune în creatologie (Introduction to Creativity). Timişoara, Editura Augusta. Romania.

[11] Csíkszentmihályi, M. (2008) Kreativitás-A flow és a felfedezés, avagy a találékonyság pszichológiája (Creativity-Psychology of the Adventures). Akadémiai Kiadó, Hungary.

[12] Zoltayné Paprika, Z. (2002) Döntéselmélet. Alinea Kiadó, Budapest.

[13] Twersky, A. and Kahneman, D. (1974) Judgment under Uncertainity: Heuristics and Biases. Science, 185, 1124-1131. http://dx.doi.org/10.1126/science.185.4157.1124

[14] Lichtenstein, S. and Fischhoff, B. (1977) Do Those Who Know More Also Know More about How Much They Know? Organizational Behaviour and Human Performance, 20, 159-183. http://dx.doi.org/10.1016/0030-5073(77)90001-0

Submit or recommend next manuscript to SCIRP and we will provide best service for you:

Accepting pre-submission inquiries through Email, Facebook, LinkedIn, Twitter, etc.

A wide selection of journals (inclusive of 9 subjects, more than 200 journals)

Providing 24-hour high-quality service

User-friendly online submission system

Fair and swift peer-review system

Efficient typesetting and proofreading procedure

Display of the result of downloads and visits, as well as the number of cited articles

Maximum dissemination of your research work

Submit your manuscript at: http://papersubmission.scirp.org/

Or contactwjet@scirp.org 